\title{
THERMAL CONDUCTIVITY AND STABILITY OF MULTILAYERED THERMAL BARRIER COATINGS UNDER HIGH TEMPERATURE ANNEALING CONDITIONS
}

Amarendra K. Rai ${ }^{1}$, Michael P. Schmitt ${ }^{2}$, Rabi S. Bhattacharya ${ }^{1}$, Dongming Zhu ${ }^{3}$, and Douglas E. Wolfe ${ }^{2}$

${ }^{1}$ UES, Inc, 4401 Dayton-Xenia Road, Dayton, Ohio 45432-1894

${ }^{2}$ Material Science and Engineering Dept., The Pennsylvania State University, University Park, PA 16802

${ }^{3}$ NASA Glenn Research Center, Cleveland, OH 44135

\begin{abstract}
Pyrochlore oxides have most of the relevant attributes for use as next generation thermal barrier coatings such as phase stability, low sintering kinetics and low thermal conductivity. One of the issues with the pyrochlore oxides is their lower toughness and therefore higher erosion rate compared to the current state of the art TBC material, yttria (6-8 wt. \%) stabilized zirconia (YSZ). In this work, sintering characteristics were investigated for novel multilayered coating consisted of alternating layers of pyrochlore oxide viz $\mathrm{Gd}_{2} \mathrm{Zr}_{2} \mathrm{O}_{7}$ and t' low $\mathrm{k}$ (rare earth oxide doped YSZ). Thermal gradient and isothermal high temperature $\left(1316^{\circ} \mathrm{C}\right)$ annealing conditions were used to investigate sintering and cracking in these coatings. The results are then compared with that of relevant monolayered coatings and a baseline YSZ coating.
\end{abstract}

Keywords: TBC, YSZ, Pyrochlore Oxides, Thermal conductivity, Sintering

† Corresponding author, E- mail address: arai@ues.com, Tel.: 19374266900 


\subsection{INTRODUCTION}

The current thermal barrier coating (TBC) material, 6-8 wt\% yttria stabilized zirconia (herein referred to as Std. YSZ), exhibits the necessary attributes to maintain the turbine engine metal components' temperature at required level. These properties include relatively low thermal conductivity, high thermal expansion coefficient and high erosion resistance. Std. YSZ is also in thermochemical equilibrium with the thermally grown oxide (TGO) at the bond coat/Std.YSZ interface and exhibits the metastable t' phase which provides high toughness. However, Std. YSZ is inadequate for the higher temperatures necessary for enhanced efficiency of gas turbine engines. This is due to an elevated temperature induced thermal instability, increased sintering rates and inferior thermal conductivity.

For TBC applications beyond $1200^{\circ} \mathrm{C}$, pyrochlore oxides of the rare earth zirconates are promising substitutes for Std. $\mathrm{YSZ}^{1-8}$. Specifically, gadolinium zirconate $\left(\mathrm{GZO}-\mathrm{Gd}_{2} \mathrm{Zr}_{2} \mathrm{O}_{7}\right)$ has been studied by several authors due to its high thermal stability ceiling, low thermal conductivity, relatively large coefficient of thermal expansion and reduced propensity for sintering ${ }^{2-6}$. Drawbacks of GZO and other rare earth zirconates are the very low toughness and thereby very poor erosion performance of the cubic structure as well as the instability with the $\mathrm{TGO}^{1,7}$. It has been suggested that the latter can be circumvented by first depositing a Std. YSZ interface layer before GZO deposition, thus preventing diffusion of the Gd into the TGO layer ${ }^{1}$.

Doping $\mathrm{ZrO}_{2}$ with trivalent rare earth oxides such as $\mathrm{Gd}_{2} \mathrm{O}_{3}$ and $\mathrm{Yb}_{2} \mathrm{O}_{3}$ has been shown to create immobile defect clusters within the structure ${ }^{9}$. These defect clusters serve to reduce thermal conductivity and provide sintering resistance, while increasing toughness and phase stability ${ }^{10}$. Below approximately 6 mol\% of total dopant, YSZ maintains the t' structure ( $\mathrm{t}$ ' low $\mathrm{k}$ ) and thus higher toughness, while above 6 mol\%, the cubic structure (cubic low $\mathrm{k}$ ) is stable ${ }^{11}$. This is important, as increasing the dopant concentration is favorable in terms of reducing thermal conductivity but will compromise toughness and therefore erosion resistance. There appears to be a need to develop technologies to impart toughness to materials such as GZO and cubic low $\mathrm{k}$ for higher temperature TBC applications.

In an attempt to increase erosion resistance with respect to GZO while maintaining its lower thermal conductivity and increased sintering resistance with respect to Std. YSZ, the present authors have initiated a systematic study to evaluate the potential of multilayered TBC architectures consisting of alternate layers of $t^{\prime}$ low $k$ and $\mathrm{GZO}^{12}$. It was hypothesized that multiple interfaces of the multilayered structure will provide higher toughness and enhanced scattering of heat carriers thereby decreasing erosion rate (increasing erosion resistance) and thermal conductivity, respectively. It was further hypothesized that such multilayered design with adequate microstructure will provide elevated temperature thermal conductivity close to that of GZO while providing better erosion resistance than GZO. The erosion rate of the multilayered TBCs has been compared with that of the monolayered GZO $\mathrm{TBC}^{12} \cdot \mathrm{Al}_{2} \mathrm{O}_{3}$ particles $(50 \mu \mathrm{m})$ were used as erodent and the erosion rate was determined by measuring the weight loss of TBC as a function of mass of the erodent fed. It was found that the erosion rate of GZO is an order of magnitude higher than Std. YSZ which can be reduced by $57 \%$ when utilizing a nano-multilayered structure $^{12}$. The earlier work ${ }^{12}$ has shown that multiple interfaces of the multilayered structure can provide higher toughness and enhanced scattering of heat carriers thereby drastically decreasing erosion rate with respect to GZO while maintaining a low thermal conductivity close to that of GZO.

The present work involves manipulation of the multilayered coating microstructure and design to further reduce thermal conductivity. Also, in the present work sintering characteristics of the multilayered 
coatings under thermal gradient as well as isothermal conditions were examined. For comparison purpose similar characteristics of monolayered coatings were also examined.

\subsection{EXPERIMENTAL PROCEDURE}

$2.54 \mathrm{~cm}$ diameter (Pt, Ni) Al bond coated (Howmet) Rene N5 (Sophisticated Alloys, Butler PA) buttons were used as substrate materials. For high temperature isothermal heat treatment work, $2.54 \mathrm{~cm} \times 2.54 \mathrm{~cm}$ polycrystalline $\mathrm{Al}_{2} \mathrm{O}_{3}$ substrates (Coors Tek, 99.5\% pure) were also utilized. The substrates were grit blasted and ultrasonically cleaned for $\mathbf{2 0}$ minutes in solutions of acetone and methanol with a DI water rinse and nitrogen dry after each clean. The substrates were then tack welded to a $5.08 \mathrm{~cm}$ diameter mandrel using 304 stainless steel strips. Next, the mandrel was mounted in an industrial prototype Sciaky electron beam-physical vapor deposition (EB-PVD) unit capable of using six EB-guns and three independent ingot feeders ${ }^{12}$. EB-PVD was used to fabricate TBCs of various architectures as presented in Table 1. Only one side of the substrate was coated.

Monolayers of Std. YSZ (Matrix 1), t' low k (Matrix 2) and GZO (Matrix 3) were fabricated as a baseline for comparisons with the multilayered coatings. The multilayered TBC structures (Matrices, 4, 5 and 6) were fabricated by depositing alternate layers of t' low $\mathrm{k}$ and GZO. For the nanolayered samples from Matrix 4 and 5, the necessary ingots were co-evaporated and a vapor shield was used to prevent intermixing of the vapor clouds. Rotation through each vapor cloud therefore provided a coating with alternating layers of t' low-k and GZO at individual layer thicknesses of $\sim 200 \mathrm{~nm}$. In the modified nanolayer from matrix 5 , the deposition rate was increased, compared to matrix 4, to introduce more porosity in each layer. In the thick layer from Matrix 6, the electron beam was alternated between two ingots, thus only a single ingot was evaporated at a time. This also yielded layered coatings with individual layer thicknesses on the order of $\sim 25 \mu \mathrm{m}$. The overall nominal thickness of all the monolayered and multilayered coatings was about $\sim 200-300 \mu \mathrm{m}$. Prior to the deposition of monolayered GZO, a thin $(25 \mu \mathrm{m})$ layer of Std. YSZ was deposited on top of the bond coat to maintain thermochemical stability between GZO and TGO. In the case of multilayered TBCs, $t$ ' low $k$ was the first layer ( 25 micron) deposited on top of the bond coat. In addition to Rene N5, the multilayer coatings from Matrix 6 were also deposited onto bare $\mathrm{Al}_{2} \mathrm{O}_{3}$ substrates. Further details of the coating deposition procedure are described elsewhere $^{12}$.

Thermal conductivity of the as-fabricated TBCs was measured by the steady-state heat flux technique at NASA Glenn Research Center. Pass through heat flux and the measured temperature gradients through the ceramic coating system were used in conjunction with a one dimensional heat transfer model to calculate the thermal conductivity ${ }^{13}$. Briefly, the TBC surface temperature was maintained at $1316^{\circ} \mathrm{C}$ for 20 hours through a constant heat flux from a $3.0 \mathrm{KW} \mathrm{CO}_{2}$ laser while backside air cooling was used to maintain the desired specimen temperature. Thus the thermal conductivity tests involved thermal gradient conditions. Surface and backside temperatures were measured via optical pyrometers while a laser reflectometer measured the reflection loss at the surface. A laser delivered heat flux was calibrated using a sample of known thermal conductivity and by subtracting the laser reflection loss at the surface from the known heat flux, the pass through heat flux can be determined. The pass-through heat flux was further verified experimentally. The TBC/metal interface temperature was obtained using the known thermal conductivity of Rene N5 metal substrate. The overall thermal conductivity as functions of coating thickness, temperature and testing time was determined from the heat fluxes and the corresponding temperature gradients across the ceramic coating. Details of the thermal conductivity measurement procedure are given elsewhere ${ }^{13-14}$. 
X-ray diffraction (XRD) and scanning electron microscope (SEM) techniques were used to characterize the phase and microstructure while box furnaces were used to carry out the high temperature anneals.

\subsection{RESULTS AND DISCUSSIONS}

Thermal conductivity results of all the fabricated TBC systems from Table 1 are shown in Figure 1 . The monolayered Std. YSZ exhibited the highest initial or "as deposited" thermal conductivity of $\sim 1.45 \mathrm{~W} / \mathrm{m}$ $\mathrm{K}$, along with the highest "sintered" thermal conductivity of $2.2 \mathrm{~W} / \mathrm{m}-\mathrm{K}$ after a full 20 hours of high heat flux testing at $1316^{\circ} \mathrm{C}$. The increase in thermal conductivity of Std. YSZ after 20 hours was $~ 52 \%$. The, t' low k and GZO monolayered coatings have initial thermal conductivity much lower than Std. YSZ with values of $1.25 \mathrm{~W} / \mathrm{m}-\mathrm{K}$ and $1.13 \mathrm{~W} / \mathrm{m}-\mathrm{K}$, respectively. The sintered thermal conductivity values were also significantly lower than Std. YSZ with t' low k exhibiting a value of $1.66 \mathrm{~W} / \mathrm{m}-\mathrm{K}$ and GZO exhibiting a value of $1.43 \mathrm{~W} / \mathrm{m}-\mathrm{K}$. It is known that in addition to coating chemistry, thermal conductivity is also a function of the overall coating microstructure, i.e. porosity level and morphology. For example, the thermal conductivity of the multilayered coating from Matrix 4 was found to be $1.3 \mathrm{~W} / \mathrm{m}-\mathrm{K}$, a value higher than that of its constituents. It was thought that the observed higher thermal conductivity of the multilayered coating was most likely due to increased coating density of a non-optimized microstructure $^{12}$. As a result, additional multilayered t' low k-GZO coatings were fabricated in Matrix 5 with the intent of a modified, more porous microstructure. The thermal conductivity of Matrix 5 was measured to be $1.14 \mathrm{~W} / \mathrm{m}-\mathrm{K}$ (Figure 1) which is lower than t' low $\mathrm{k}$ and closer to GZO. The sintered thermal conductivity of Matrix 5 increased by $7 \%$ to $1.22 \mathrm{~W} / \mathrm{m}-\mathrm{K}$, a much smaller increase than the observed 52\% increase of Std. YSZ. This observation reveals that t' low k-GZO multilayer TBC system with adequate microstructure can provide lower thermal conductivities and sintering rates compared to Std. YSZ.

Sintering characteristics of the monolayered and multilayered TBCs from Table 1 were also examined by analyzing their microstructure after thermal conductivity testing was conducted under thermal gradient conditions. Figures 2 (a,b,c,d) represent the surface SEM micrographs, respectively, of Matrix 1-4 after sintering for $20 \mathrm{hrs}$ at $1316^{\circ} \mathrm{C}$. Sintering of column tips occurred in each sample and, except for GZO, surface cracks were observed on the surface of each sample. A closer examination of surface cracks revealed that the cracks in Std. YSZ (Figure 2a) were relatively wider than those in t' low k (Figure 2b) and multilayered t' low k-GZO (Figure 2d). Thus it appears that rare earth oxide doping and layering helps in decreasing the extent of cracking. This observation reveals that by manipulating the doping level and coating architecture, the extent of sintering induced cracking can be minimized. This is also in agreement with thermal conductivity tests which suggested smaller increases in thermal conductivity over time and therefore reduced sintering of doped and multilayered TBC. It is known that for EB-PVD thermal barrier coatings high porosity is present in the in-plane directions between the columnar grains. Welding of the individual columnar grains has been observed in sintered EB PVD TBCs which in turn created through thickness cracks in order to relieve stress ${ }^{11}$. Figures 3 (a,b,c,d) represent X-SEM micrographs Matrix 1-4, respectively, after sintering for 20 hrs at $1316^{\circ} \mathrm{C}$. Relatively wider and longer through thickness (vertical) cracks reaching to the TBC/TGO interface were observed in Std. YSZ (Figure 3a). A considerable amount of column sintering close to the surface and inside the coating was also observed. In t' low k (Figure 3b), most cracks were shorter and terminated within the coatings. Only a few long cracks were observed and they did not appear to be as wide as those observed in the Std. YSZ, further confirming the surface observations. Some sintering of the columns at the coating surface and inside the coating was observed, but not as extensively as in std. YSZ, indicating an increased thermal stability imparted via the addition of rare earth dopants. No cracks were observed in GZO (Figure 3c) and while sintering of the closely spaced columns was observed, more inter-columnar porosity appears to be preserved compared to Std. YSZ (Figure 3a) and t' low k (Figure 3b). Only shorter length cracks were observed in the sintered multilayered t' low k- GZO sample (Figure 3d) and these appeared to be 
terminated within the coating. Sintering of the columns close to the surface and inside the coating was observed, but again, significantly less than in the Std. YSZ. Horizontal cracks confined between the vertical cracks were also observed at certain depths (marked by arrows) which could indicate deflection of vertical cracks and enhanced toughness in the multilayered TBC. It is interesting to see that the observed horizontal cracks are located in a localized region confined to the middle of the multilayered TBC. Similar to surface SEM observations in Figure 2, the cross sections shown in Figure 3 also indicate that rare earth oxide doped YSZ ( $t$ ' low k) and multilayer (t' low k-GZO) TBCs are very effective in mitigating crack-propagation. Absence of cracks in GZO could be related to its intrinsically low sintering rate. At present, the reason for the observed horizontal cracks in the t' low k-GZO multilayer (Matrix 4) is not very clear. This could be related with the localized denser microstructure and/or composition. The longer cracks observed in monolayered Std. YSZ are wider close to the surface and the crack width decreases through the coating thickness. During thermal conductivity testing the surface temperature is expected to be the highest and therefore sintering induced volume change would be higher at the surface compared to that in the bulk of the coating which in turn will create wider cracks at the surface. Compared to Std. YSZ, the crack widths appeared to be narrower in monolayered t' low $\mathrm{k}$ and multilayered TBCs. Lower sintering rates of t' low $\mathrm{k}$ and multilayered TBCs are expected to lower the volume change in the surface region which in turn could be responsible for decreased crack widths. Doping and multilayering induced increased toughness could be the reason for shorter crack length in monolayered t' low k and multilayered t' low k-GZO TBCs.

The sintering characteristics of the multilayer TBC with improved microstructure from Matrix 5 were also examined via the post thermal conductivity cross sectional micrographs in Figure 4. No indication of horizontal cracks was found. This observation lends credence to the notion that the observed horzontal cracks in Matrix 4 could be due to denser microstructure. Judging from the microstructures of Matrix 4 (Figure 3d) and Matrix 5 (Figure 4), it appears that even after thermal conductivity test, the microstructure of Matrix 5 is more porous than that of Matrix 4.

A question comes to mind whether the observed sintering induced cracking after thermal conductivity testing is due to the initial microstructure and porosity level or due to the materials' intrinsic characteristics and/or coating architecture. Ideally to answer this question one has to start out with the TBCs having identical microstructure and evaluate their sintering characteristics at higher temperature. Obtaining TBCs of different chemistry with identical microstructure in different EB-PVD runs is nontrivial. A simpler approach would be to deposit two TBC compositions in a single EB-PVD run as one TBC system. With that in mind, a multilayer of t' low k-GZO with thicker $(\sim 25 \mu \mathrm{m})$ individual layers were fabricated on bond coated Rene N5 and alumina substrates in Matrix 6. Another purpose of fabricating thicker multilayer of t' low k-GZO was to examine the interaction between t' low k and GZO at higher temperature and longer anneal times. Alumina substrates were used to examine the sintering behavior of thicker multilayer at higher temperature $\left(1316^{\circ} \mathrm{C}\right)$ without the need for cooling the back side. Thermal conductivity of the thicker multilayer on bond coated Rene N5 substrate was determined under identical conditions and found to be $\sim 1.10 \mathrm{~W} / \mathrm{m}-\mathrm{K}$ (Figure 1). Figure 5 represents surface SEM micrographs of the thicker multilayer before (pre TC) and after (post TC) thermal conductivity test. Almost no visible cracks were observed. Figure 6 represents the cross section micrographs of an as deposited thicker multilayer on alumina substrate. In the backscattered cross section image, the GZO layers appear as the bright phase. The microstructure appears relatively porous and the inter-columnar gaps are continuous through individual layers of both materials viz. $t$ ' low $\mathrm{k}$ and GZO. Thus from this level of microstructural characterization, it appears that porosity (gap between columns) along in-plane direction is similar in both materials. The thicker multilayers were isothermally annealed at $1316^{\circ} \mathrm{C}$ for 20, 100 and 500 hours. Figure 7 (a,b,c) show the surface SEM micrographs of the annealed thicker multilayer samples. After 20 hrs. of annealing, the surface appears almost crack free; however, some cracking was observed after annealing at 100 and 500 hours. The observed cracks (Figure 7b and 7c) 
appear to be the separation between columns of the individual layers of the multilayered structure. This was verified from the X-SEM micrographs shown in Figure 8 (a,b,c). Noticeable sintering was observed in each of the individual layers. Careful observation indicates that the reduction in the inter-columnar spacing in t' low k layer is larger than in GZO layer which implies that the extent of sintering is much higher in t' low k layers than in GZO layers. In other words even with similar in-plane direction porosity level, GZO is more sintering resistant than t' low $\mathrm{k}$. The multilayered structures appear to minimize through thickness cracking which is prevalent in Std. YSZ. Thus the observed cracking in monolayered Std. YSZ and t' low k after thermal conductivity test could assigned to their higher sintering rate.

The observation that more porous multilayer from Matrix 5 exhibits lower thermal conductivity than denser multilayer from Matrix 4 demonstrates the importance of microstructure in lowering thermal conductivity. On the same token it can be argued that the thermal conductivity of Std. YSZ can also be lowered considerably by introducing adequate porosity. However, due to the observed higher intrinsic sintering rate of Std. YSZ thermal conductivity of porous Std. YSZ will increase greatly with concomitant introduction of through thickness cracks.

To examine relatively longer term microstructural stability, the thicker t' low k-GZO multilayer samples isothermally annealed at $1316^{\circ} \mathrm{C}$ for 100 and 500 hours were examined critically. Figures 9 presents backscattered X-SEM micrographs (a,b) and EDS maps (c,d) of an interface in a Matrix 6 multilayer coating which has been annealed for 100 (a,c) and 500 hrs (b,d). From the back scattering contrast it appears that the edges of the columns of the t' low k layers are composed of a higher $\mathrm{Z}$ element and the maps shown in Figure 9 (c and d) confirm the element is Gd. With increased annealing time the Gd containing column edges of t' low $\mathrm{k}$ increasingly sinter together. The unsintered portion of the intercolumnar gap appeared mostly as dark circular and sometimes as dark elongated regions. The intercolumnar gaps in the GZO layers appear to widen with anneal time. These two observations indicate that at the interfaces of t' low k/GZO where the columns of the two layers meet, Gd from the GZO layer diffuses along the column edges of the t' low k layer and with increased time (500 hours) ultimately the columns in the $\mathrm{t}^{\prime}$ low $\mathrm{k}$ layers sintered together. The observed widening of the intercolumnar gaps in the GZO layers could be the consequence of the Gd out diffusion (material transport) to the column edges of t' low k.

The observed migration of Gd to the column edges of t' low k, under the given condition, could be due to the chemical potential difference between the two involved phases viz. GZO and t' low k and/or due to the fabrication process induced. Study on the diffusion couples such as GZO/t' low k and GZO/std. YSZ would be helpful in resolving this issue. Knowing the mechanism of CMAS resistance of GZO where Gd is involved in the formation of fluorite and apatite phases at the column edges to block CMAS penetration $^{15}$, creating a microstructure with Gd at the column edges of t' low k layers, could be very helpful for CMAS resistance.

Finally it should be emphasized that the thermal conductivity tests were carried out under thermal gradient conditions which is similar to the field application where the TBC coated blades are internally cooled. Thus, the thermal conductivity test at NASA Glenn Research Center could be used for design, development and life prediction for engine application ${ }^{13}$.

\subsection{SUMMARY AND CONCLUSIONS}

Fabrication and evaluation of t' low k-GZO multilayered TBC was initiated in an effort to develop TBC having thermal conductivity comparable to GZO yet with much lower erosion rates than GZO. In the present work we have shown that the t' low k-GZO multilayered TBC with adequate microstructure can provide lower thermal conductivity at higher temperature. Sintering characteristics of the multilayered 
TBC under thermal gradient conditions were examined and compared with that of monolayered Std. YSZ, t' low $\mathrm{k}$ and GZO. It has been shown that the multilayered TBC is able to minimize the sintering induced cracking that is prevalent in Std. YSZ and to a lesser extent in t' low k. Out-diffusion of Gd from GZO layer was observed under higher temperature and longer term annealing conditions. Much more work including higher temperature erosion, thermal stability, and furnace cycling test would be needed to establish the multilayered coating architecture as a future high temperature TBC.

\section{REFERENCES}

[1] Levi CG. Emerging materials and processes for thermal barrier systems. Curr Opin Solid St Mater Sci 2004;8:77-91.

[2] Vassen R, Cao X, Tietz F, Basu D, Detlev S. Zirconates as New Materials For Thermal Barrier Coatings. J Am Ceram Soc 2000;8:2023-8.

[3] Maloney M. J. US Patent No. 6,117,560. 2000

[4] Wu J, Wei X, Padture N, Klemens P, Gell M, Garcia E, et al. Low-Thermal Conductivity Rare Earth Zirconates for Potential Thermal Barrier Coating Applications. J Am Ceram Soc 2002;85:2031-5

[5] Kramer S, Yang J, Levi CG. Infiltration inhibiting reaction of gadolinium zirconate thermal barrier coatings with CMAS melts. J Am Ceram Soc 2008;91:576-83.

[6] Vaben R, Jarligo MO, Steinke T, Mack DA, Stover D. Overview on advanced thermal barrier coatings. Surf Coat Technol 2010;205:938-42.

[7] Wolfe DE, Singh J, Miller R, Eldridge J, Zhu D. Tailored Microstructure of EB-PVD 8YSZ Thermal Barrier Coatings with Low Thermal Conductivity and High Thermal Reflectivity for Turbine Applications. Surf Coat Technol 2005;190:132-49.

[8] Zhao H, Begley MR, Heuer A, Sharghi-Moshtaghin R, Wadley HN. Reaction, transformation and delamination of samarium zirconate thermal barrier coatings. Surf and Coat Technol 2011;205:4355-65.

[9] Zhu D, Miller RA. Thermal Conductivity and Sintering Behavior of Advanced Thermal Barrier Coatings. In: Lin HT, Singh M, editors. 26th Annual Conference on Composites, Advanced Ceramics, Materials, and Structures: B: Ceramic Engineering and Science Proceedings, Hoboken NJ: John Wiley \& Sons Inc; 2002, p. 457-68.

[10] Zhu D, Chen YL, Miller RA, Defect clustering and nanophase structure characterization of multicomponent rare earth oxide doped zirconia-yttria thermal barrier coatings. NASA Technical Memo 212480. Cleveland OH: Glenn Research Center ; 2004, p. 1-10

[11] Zhu D, Nesbitt JA, McCue TR, Barrett CA, Miller RA. Furnace Cyclic Behavior of PlasmaSprayed Ziconia-Yttria and Multi-Component Rare Earth Oxide Doped Thermal Barrier Coatings. Ceram Eng Sci Proc 2002;23:533-45.

[12] Wolfe DE, Schmitt MP, Zhu D, Rai AK, Bhattacharya RS. Multilayered thermal barrier coating architecture for high temperature applications. In: Zhu D, Lin HT, Zhou Y, Hwang T, editors. American ceramic society proceedings, Advanced Ceramic Coatings and Materials for Extreme Environments II, The American Ceramic Society; 2013, p. 3-18.

[13] Zhu D, Miller RA, Nagaraj BA, Bruce RW. Thermal conductivity of EB-PVD thermal barrier coatigns evaluated by a steady state laser heat flux technique. Surf Coat Technol 2001;138:1-8.

[14] Zhu D, Miller RA. Thermal Conductivity and Elastic Modulus Evolution of Thermal Barrier Coatings under High Heat Flux. J Therm Spray Technol 2000;9:175-180.

[15] Levi CG, Hutchinson JW, Vidal-Setif MH, Johnson CA. Environmental degradation of thermal barrier coatings by molten deposit. MRS Bull 2012;37:932-941. 


\section{AKNOWDLEDGEMENTS}

This research was sponsored by the Department of Energy (DOE) STTR under award number DESC0004356 (Dr. Patcharin Burke). Any opinions, findings, conclusions, or recommendations expressed in this material are those of the authors and do not necessarily reflect the views of the US DOE. 
Table 1. Fabricated TBCs

\begin{tabular}{|c|c|c|c|}
\hline Matrix \# & TBC & Architecture & $\begin{array}{c}\text { Nominal Layer } \\
\text { Thickness }(\boldsymbol{\mu m})\end{array}$ \\
\hline $\mathbf{1}$ & Std. YSZ & Monolayer & 200 \\
\hline 2 & t' low k & Monolayer & 200 \\
\hline 3 & GZO & Monolayer & 200 \\
\hline 4 & t' low k-GZO & Multilayer (Nano) & $\mathbf{0 . 2 0}$ \\
\hline 5 & t' low k-GZO & $\begin{array}{c}\text { Multilayer (Modified } \\
\text { Nano) }\end{array}$ & $\mathbf{0 . 3 0}$ \\
\hline 6 & t' low k-GZO & $\begin{array}{c}\text { Multilayer (Thick } \\
\text { Layers) }\end{array}$ & 25 \\
\hline
\end{tabular}

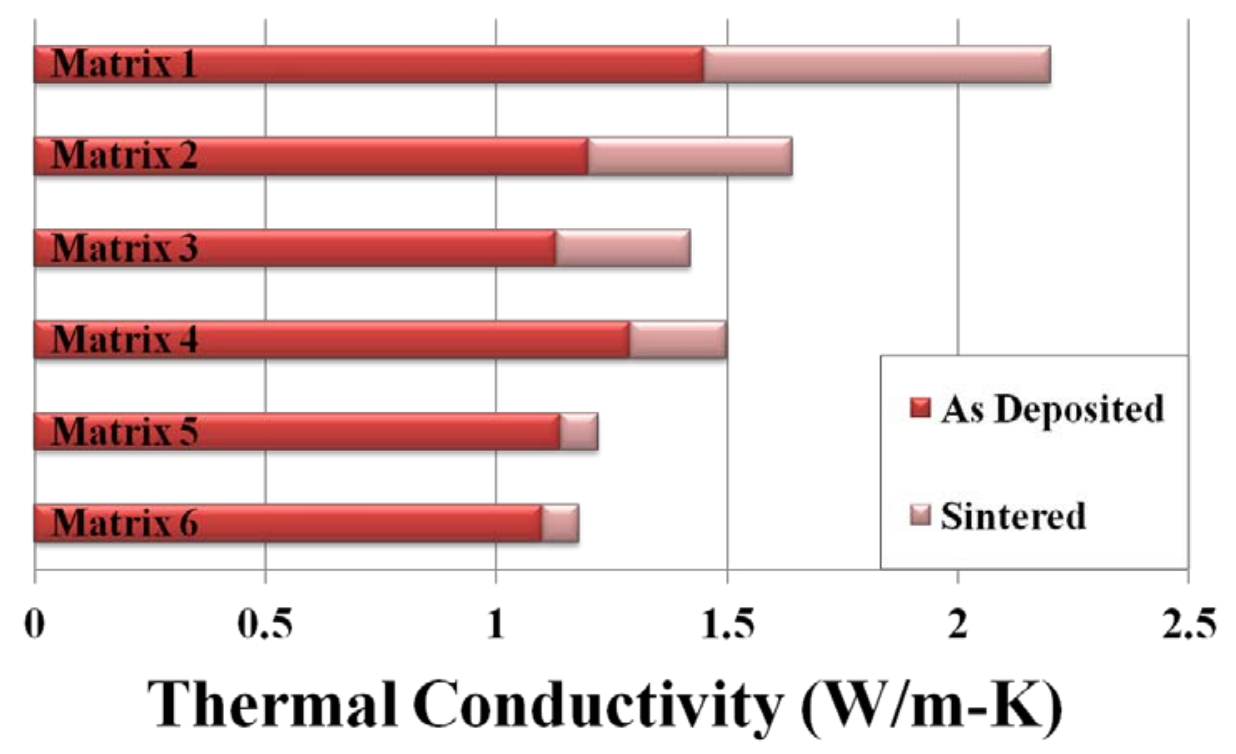

Figure 1. Plot of thermal conductivity and maximum thermal conductivity for the TBC systems shown in Table 1 

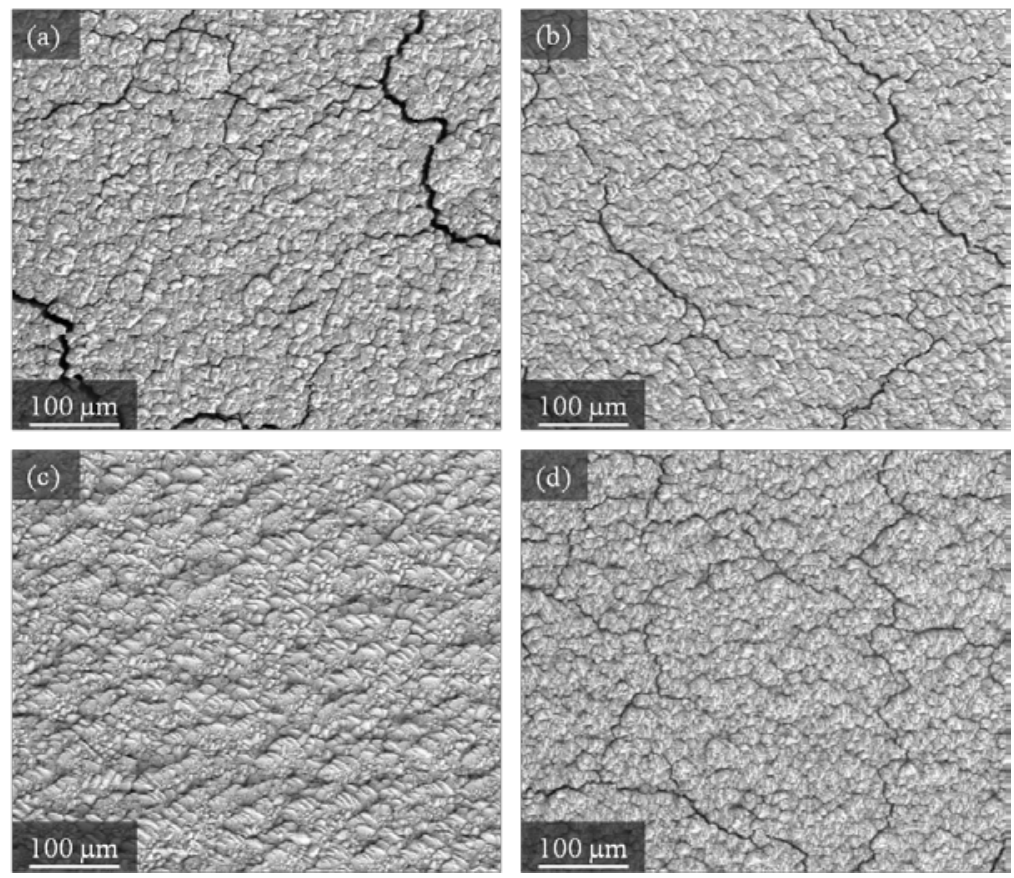

Figure 2. Surface SEM micrographs of (a) Matrix 1: Std. YSZ, (b) Matrix 2: t' low k, (c) Matrix 3: GZO and (d) Matrix 4: t' low k-GZO multilayer after thermal conductivity tests

(a)

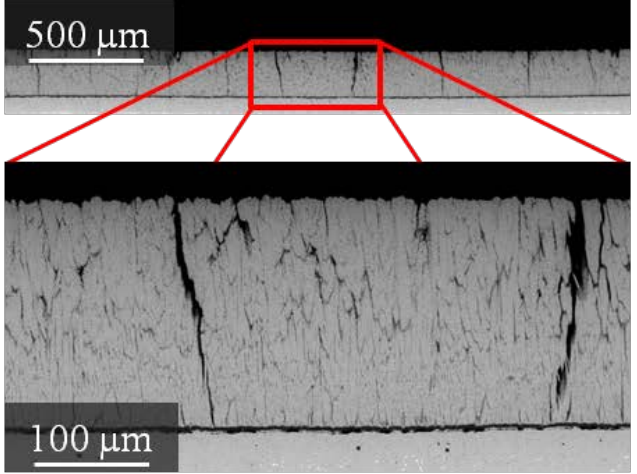

(c)

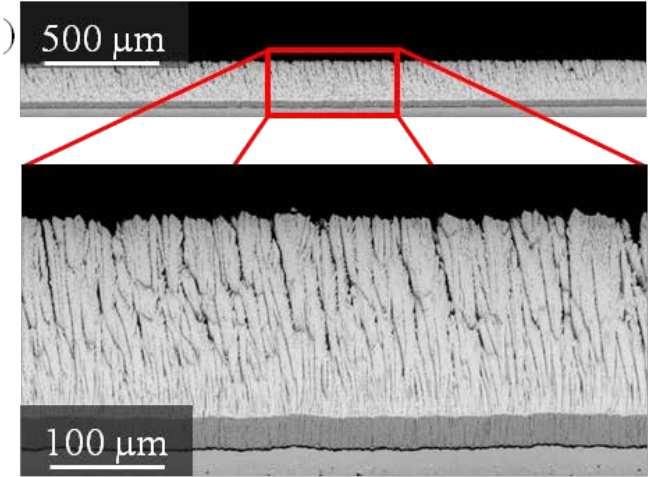

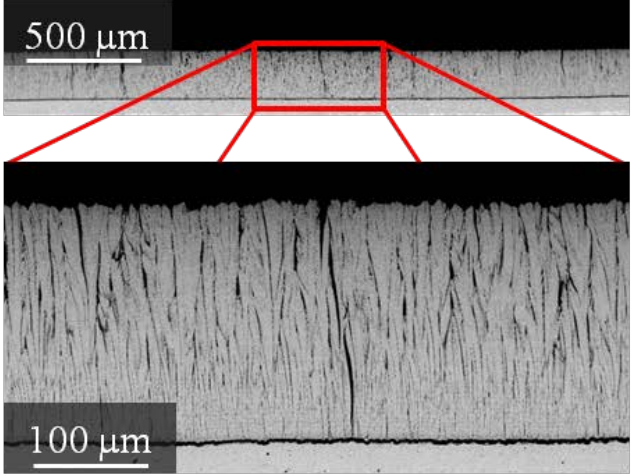

(b)

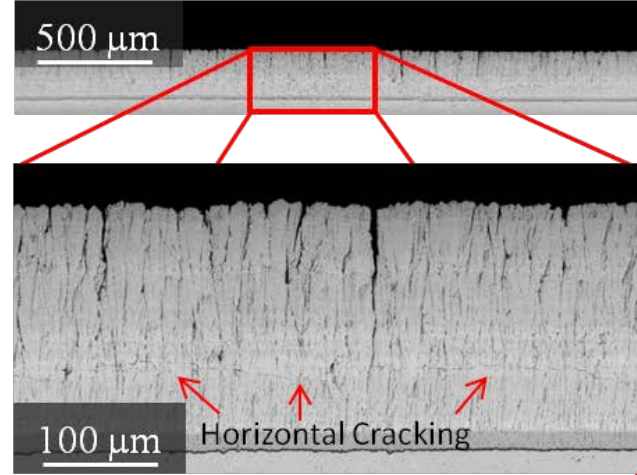

(d)

Figure 3. X-SEM micrographs of (a) Matrix 1: Std. YSZ, (b) Matrix: 2 t' low k, (c) Matrix 3: GZO and (d) Matrix 4: t' low k-GZO multilayer after thermal conductivity tests 


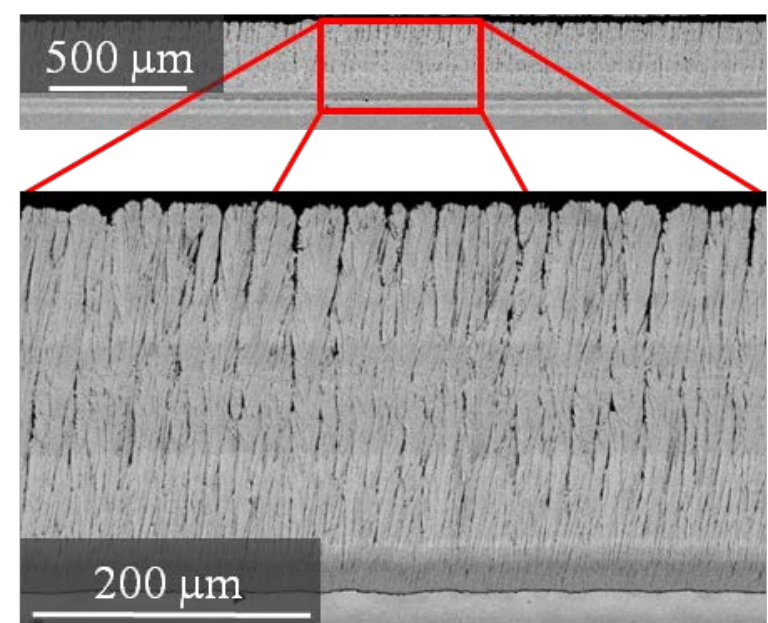

Figure 4. $X$ - SEM micrographs t' low k-GZO multilayer (Matrix 5) after thermal conductivity tests

(a)
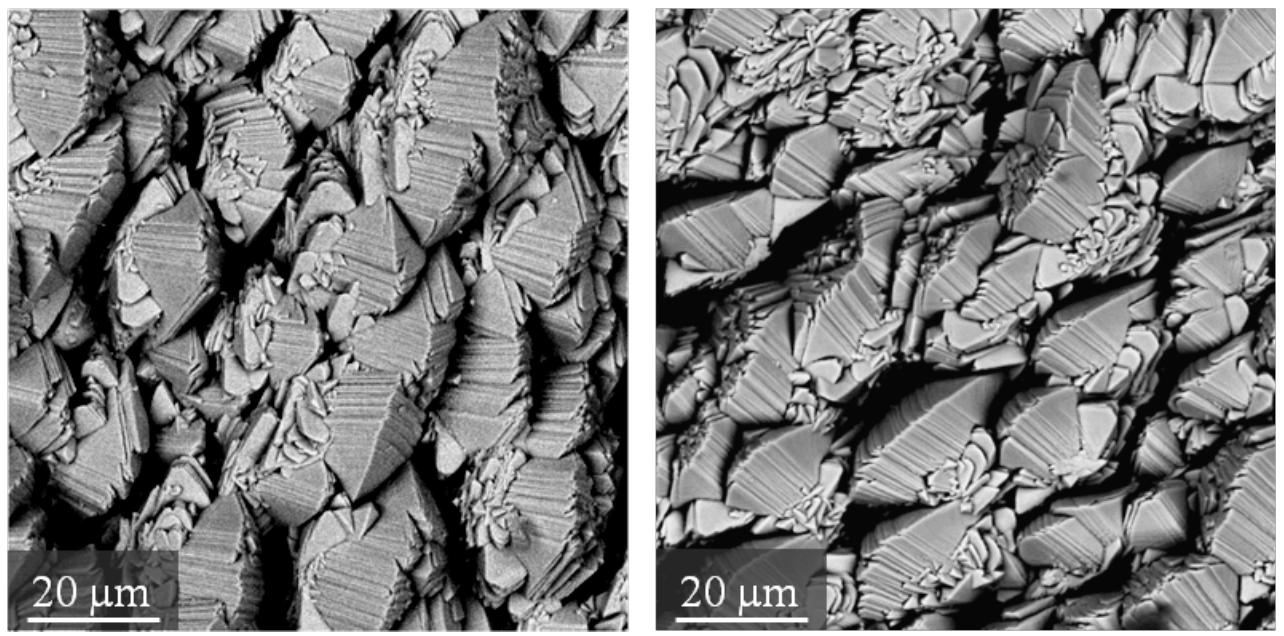

(b)

Figure 5. Surface SEM micrographs of Matrix 6: t' low k-GZO thicker multilayer (a) before and (b) after thermal conductivity test.

(a)
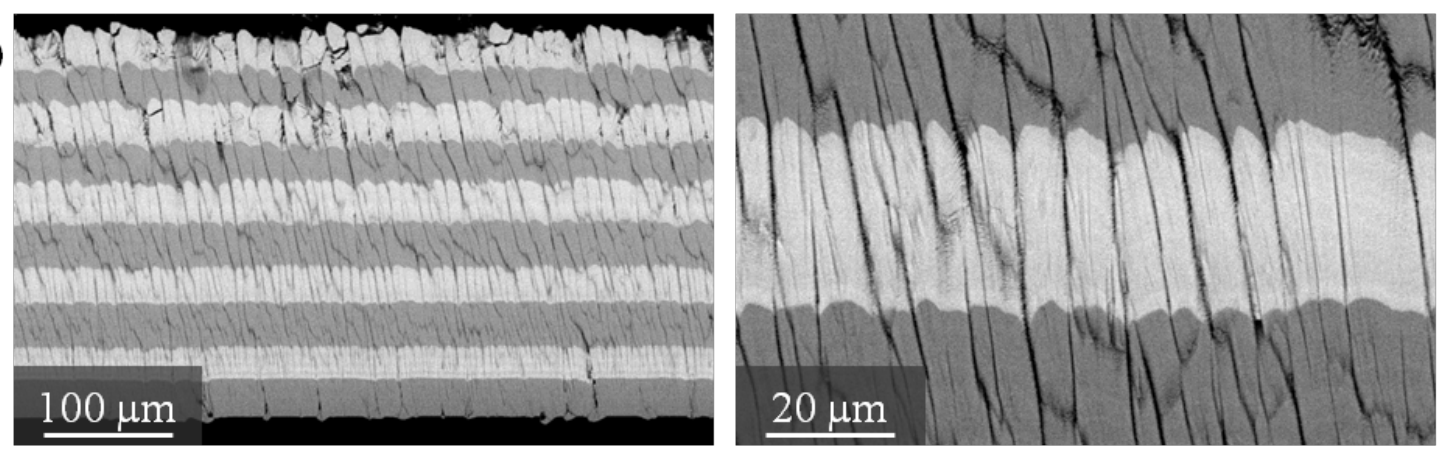

(b)

Figure 6. X-SEM micrographs of as-deposited thicker t' low k-GZO multilayer (Matrix 6) on $\mathrm{Al}_{2} \mathrm{O}_{3}$ substrate at two different magnifiations 

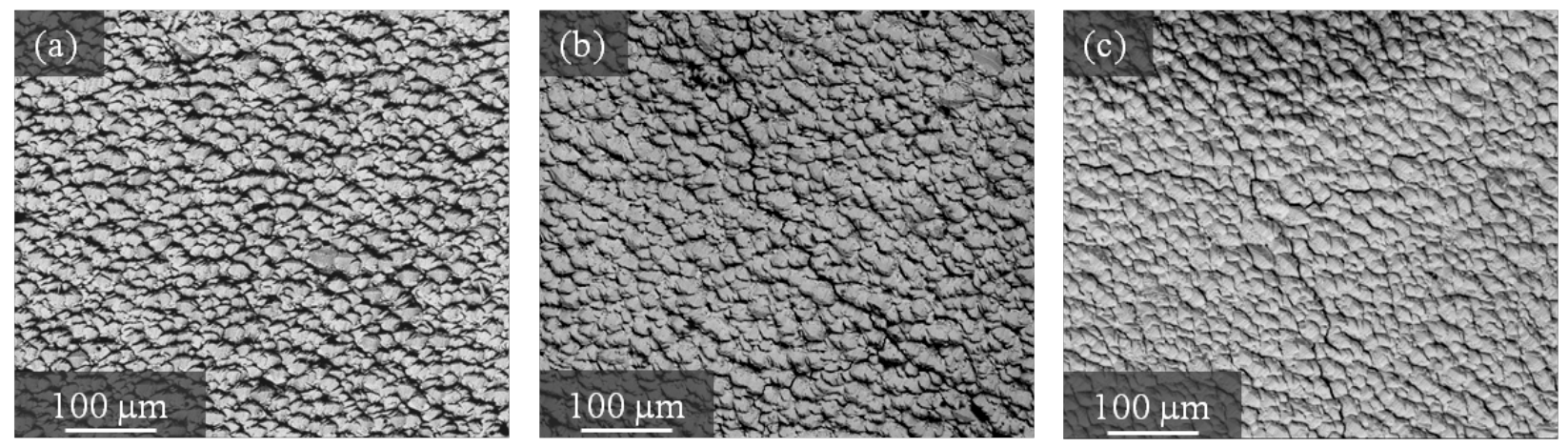

Figure 7. Surface SEM micrographs of thicker t' low k-GZO multilayer (Matrix 6) on alumina substrate after annealing at $1316^{\circ} \mathrm{C}$ for (a) 20, (b) 100 and (c) $500 \mathrm{hrs}$.
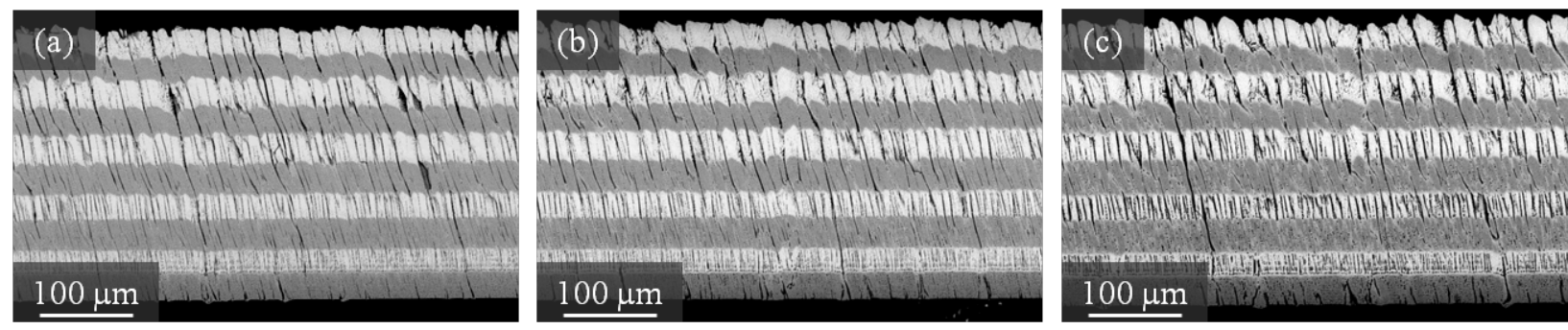

Figure 8. X-SEM micrographs of thicker t' low k-GZO multilayer (Matrix 6) on $\mathrm{Al}_{2} \mathrm{O}_{3}$ substrate after isothermal annealing at $1316^{\circ} \mathrm{C}$ for (a) 20, (b) 100 and (c) 500 hours.
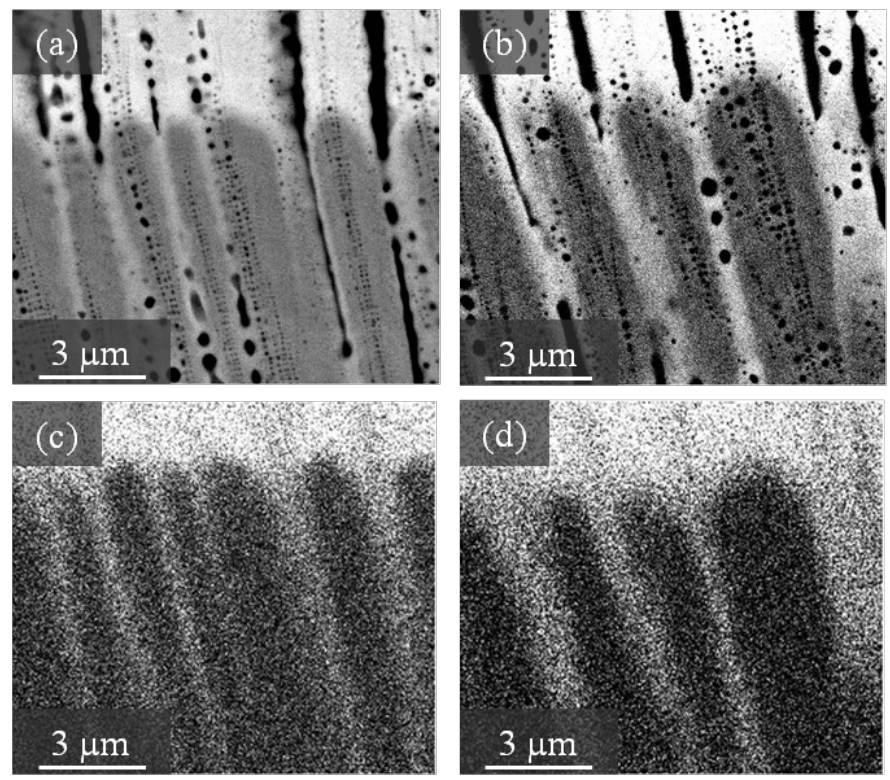

Figure 9. X-SEM micrographs of thicker t' low k-GZO multilayer (Matrix 6) on $\mathrm{Al}_{2} \mathrm{O}_{3}$ substrate showing one interface GZO/t' low $k$ after isothermal annealing at $1316^{\circ} \mathrm{C}$ for $(\mathrm{a} / \mathrm{c}) 100$ and (b/d) 500 hours with EDS mapping of Gadolinium shown in (c) and (d). 
TABLES

Table 1. Fabricated TBCs

\begin{tabular}{|c|c|c|c|}
\hline Matrix \# & TBC & Architecture & $\begin{array}{c}\text { Nominal Layer } \\
\text { Thickness }(\mu \mathrm{m})\end{array}$ \\
\hline 1 & Std. YSZ & Monolayer & 200 \\
\hline 2 & t' low k & Monolayer & 200 \\
\hline 3 & GZO & Monolayer & 200 \\
\hline 4 & t' low k-GZO & Multilayer (Nano) & 0.20 \\
\hline 5 & t' low k-GZO & $\begin{array}{c}\text { Multilayer (Modified } \\
\text { Nano) }\end{array}$ & 0.30 \\
\hline 6 & t' low k-GZO & Multilayer (Thick Layers) & 25 \\
\hline
\end{tabular}




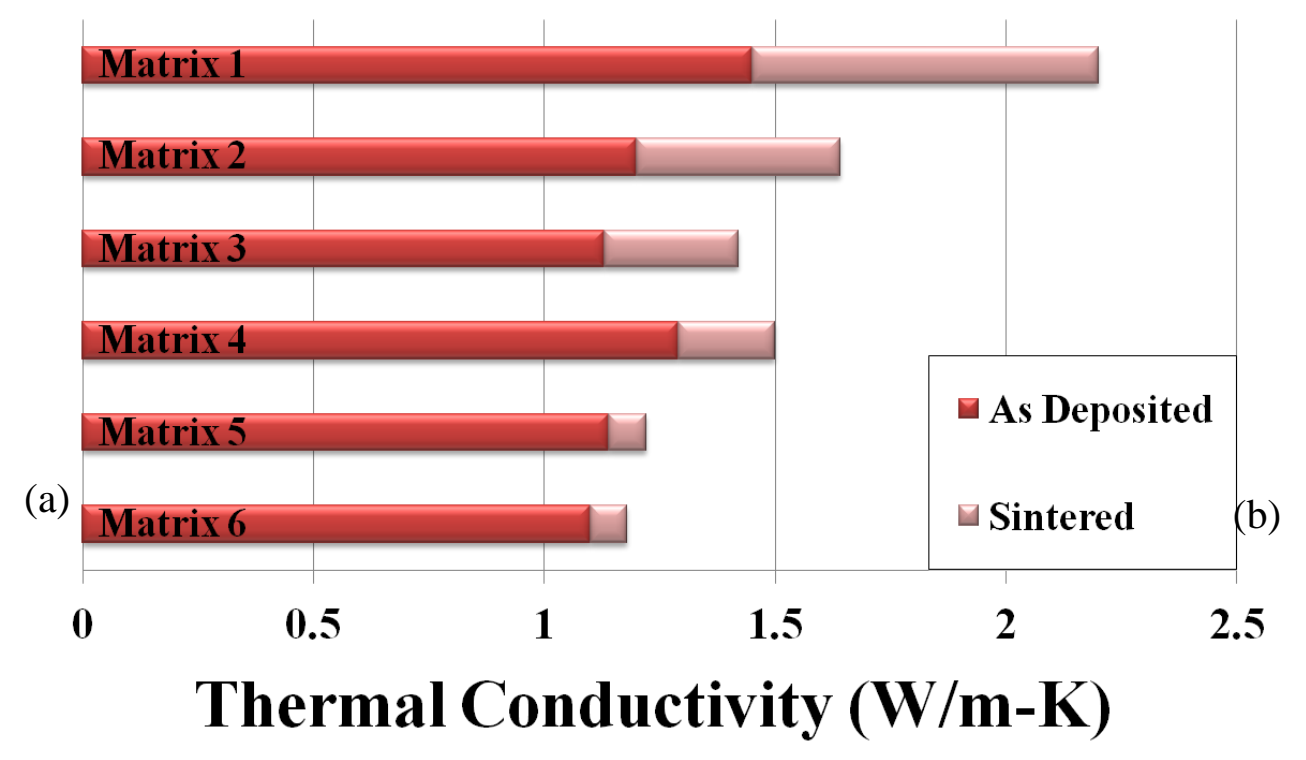

Figure 1. Plot of thermal conductivity and maximum thermal conductivity for the TBC systems shown in Table 1
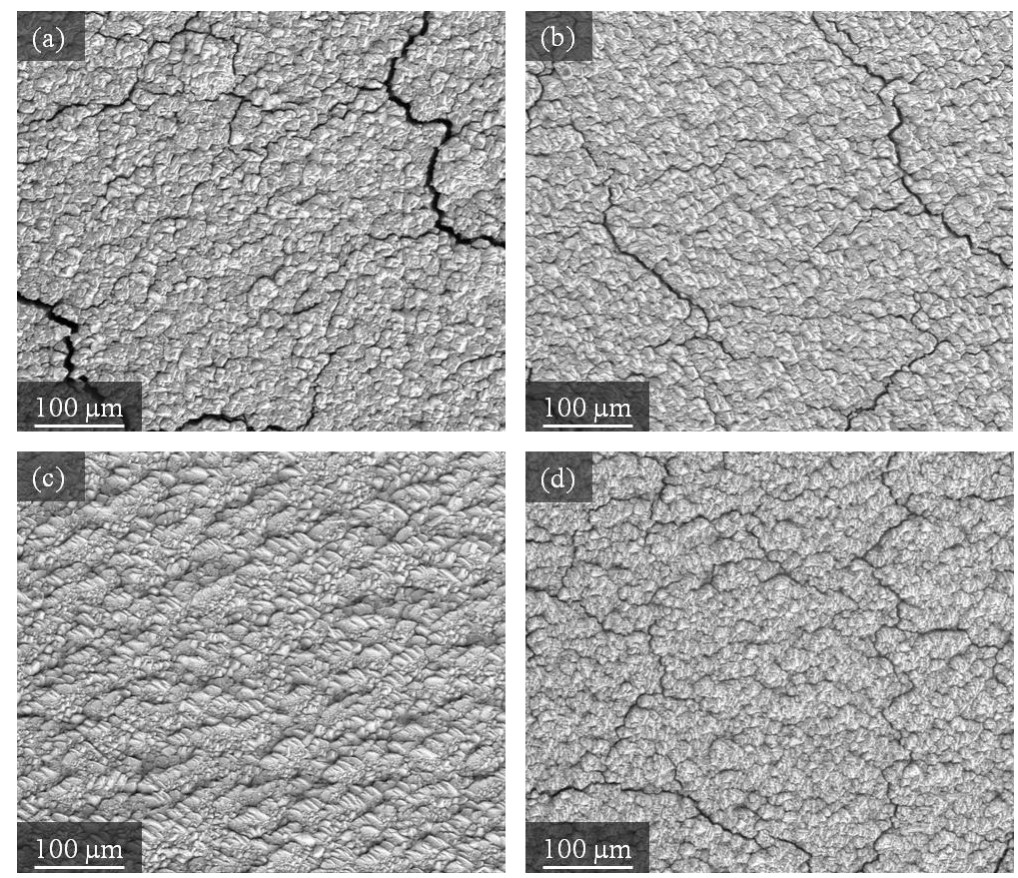

Figure 2. Surface SEM micrographs of (a) Matrix 1: Std. YSZ, (b) Matrix 2: t' low k, (c) Matrix 3: GZO and (d) Matrix 4: t' low k-GZO multilayer after thermal conductivity tests 
(a)

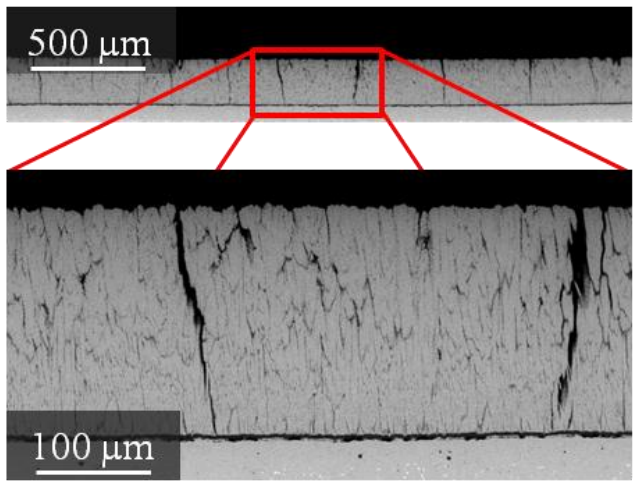

(c)

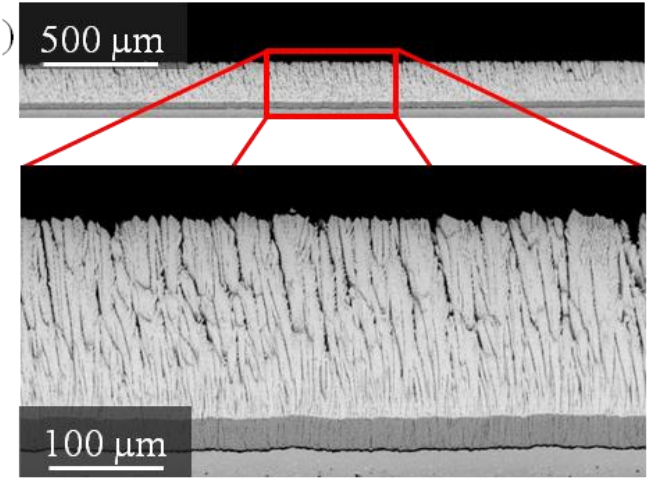

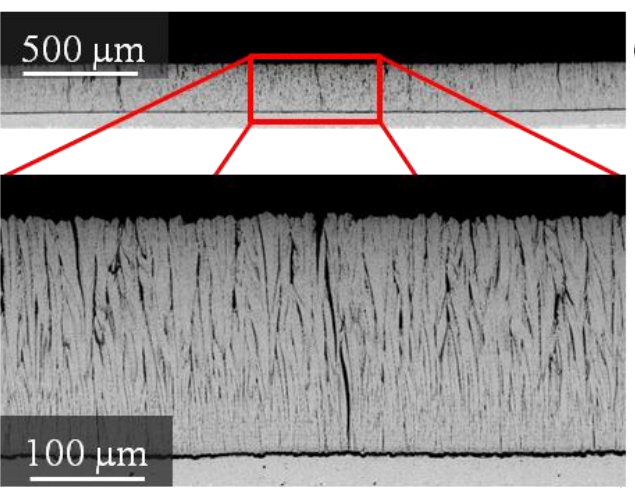

(b)

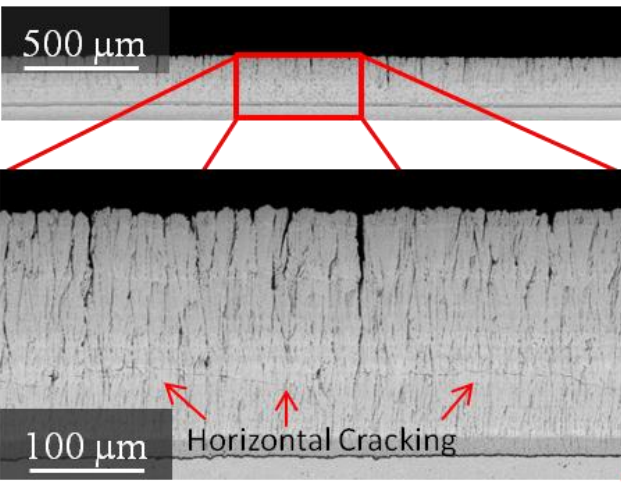

(d)

Figure 3. X- SEM micrographs of (a) Matrix 1: Std. YSZ, (b) Matrix: 2 t' low k, (c) Matrix 3: GZO and (d) Matrix 4: t' low k-GZO multilayer after thermal conductivity tests

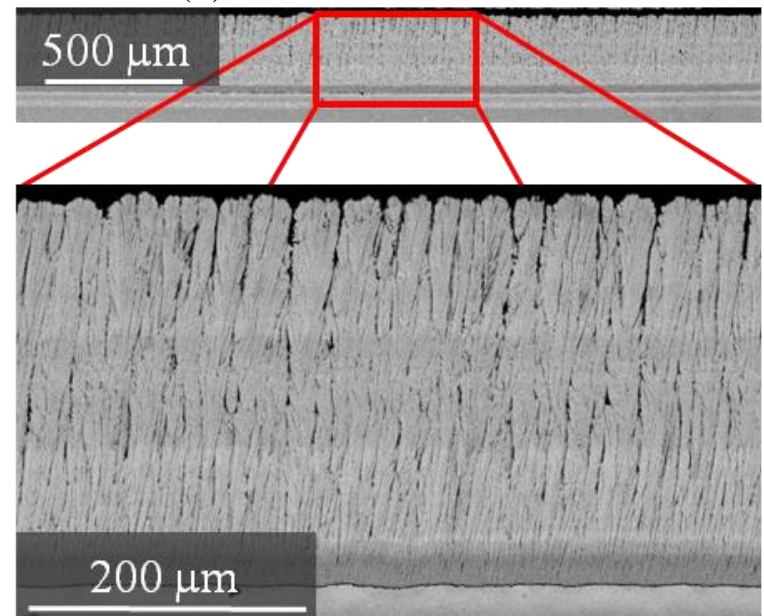

Figure 4. X-SEM micrographs t' low k-GZO multilayer (Matrix 5) after thermal conductivity tests 
(a)

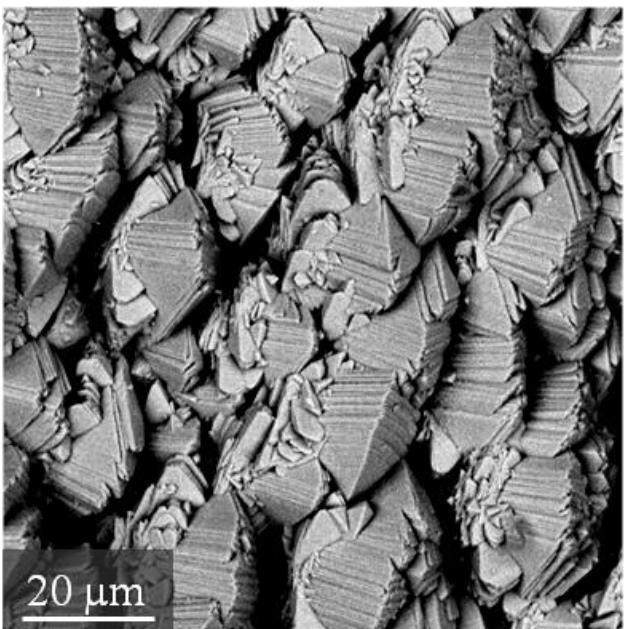

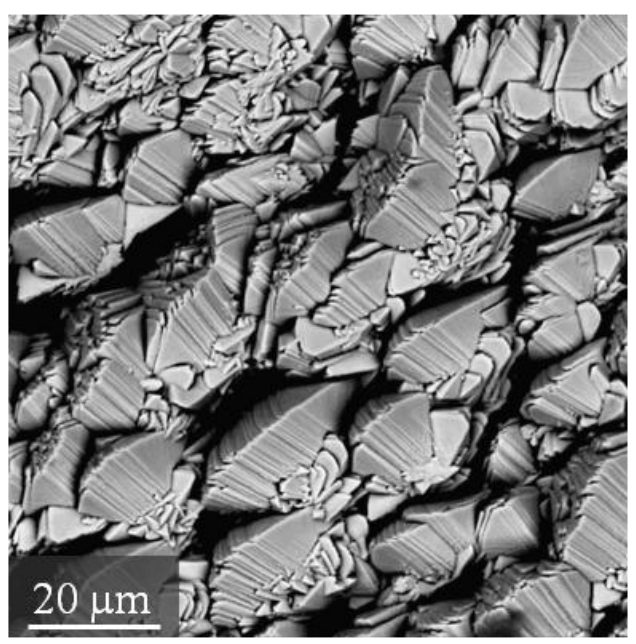

(b)

Figure 5. Surface SEM micrographs of Matrix 6: t' low k-GZO thicker multilayer (a) before and (b) after thermal conductivity test.

(a)
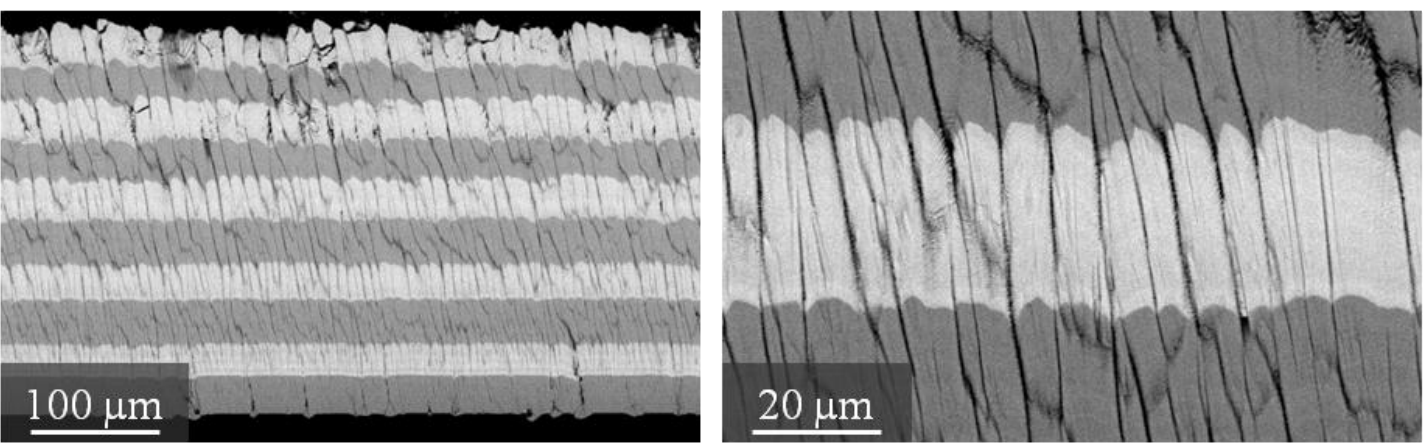

Figure 6. X-SEM micrographs of as-deposited thicker t' low k-GZO multilayer (Matrix 6) on $\mathrm{Al}_{2} \mathrm{O}_{3}$ substrate at two different magnifiations
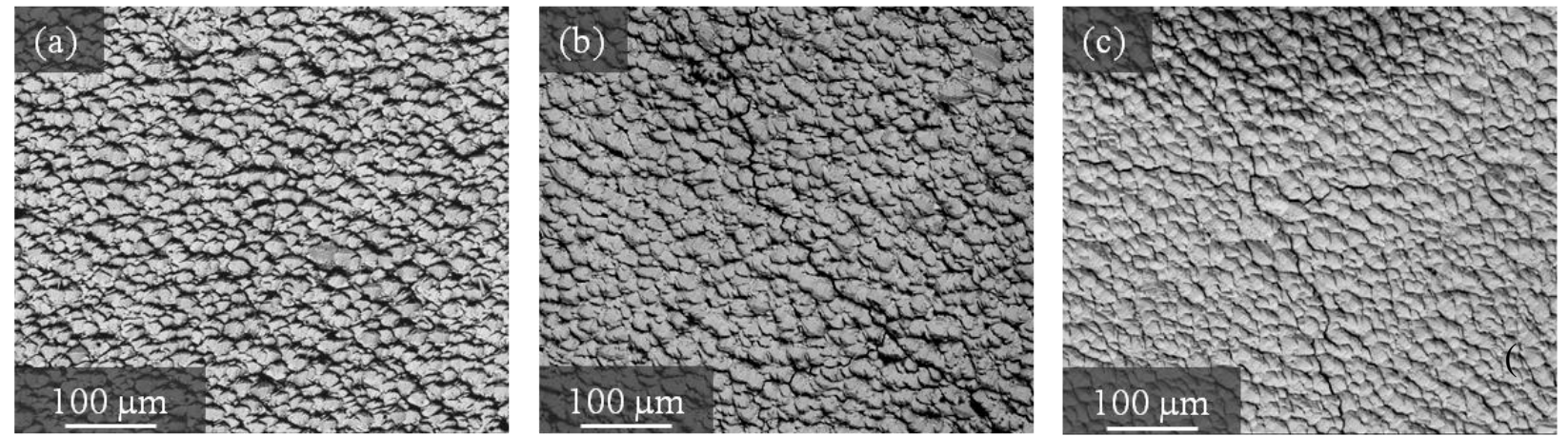

Figure 7. Surface SEM micrographs of thicker t' low k-GZO multilayer (Matrix 6) on alumina substrate after annealing at $1316^{\circ} \mathrm{C}$ for (a) 20 , (b) 100 and (c) $500 \mathrm{hrs}$. 

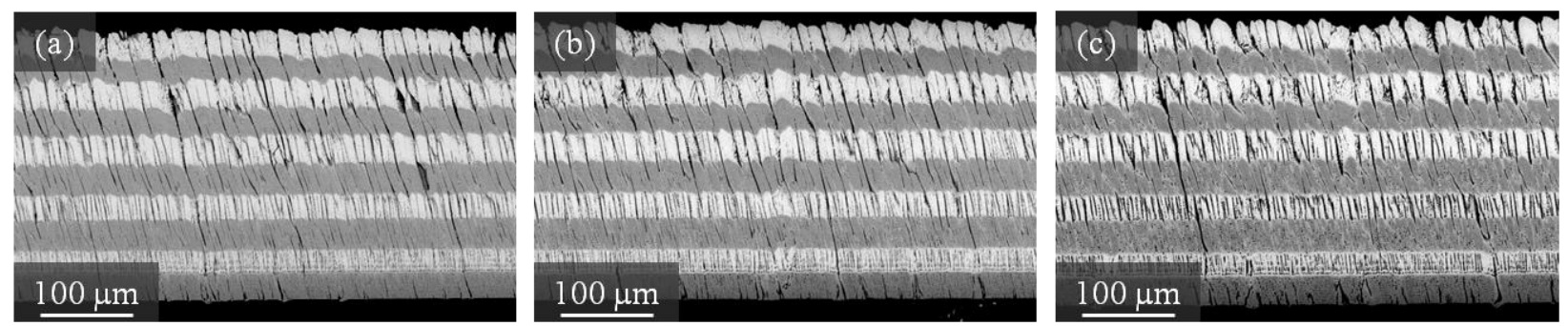

Figure 8. X- SEM micrographs of thicker t' low k-GZO multilayer (Matrix 6) on $\mathrm{Al}_{2} \mathrm{O}_{3}$ substrate after isothermal annealing at $1316^{\circ} \mathrm{C}$ for (a) 20 , (b) 100 and (c) 500 hours.
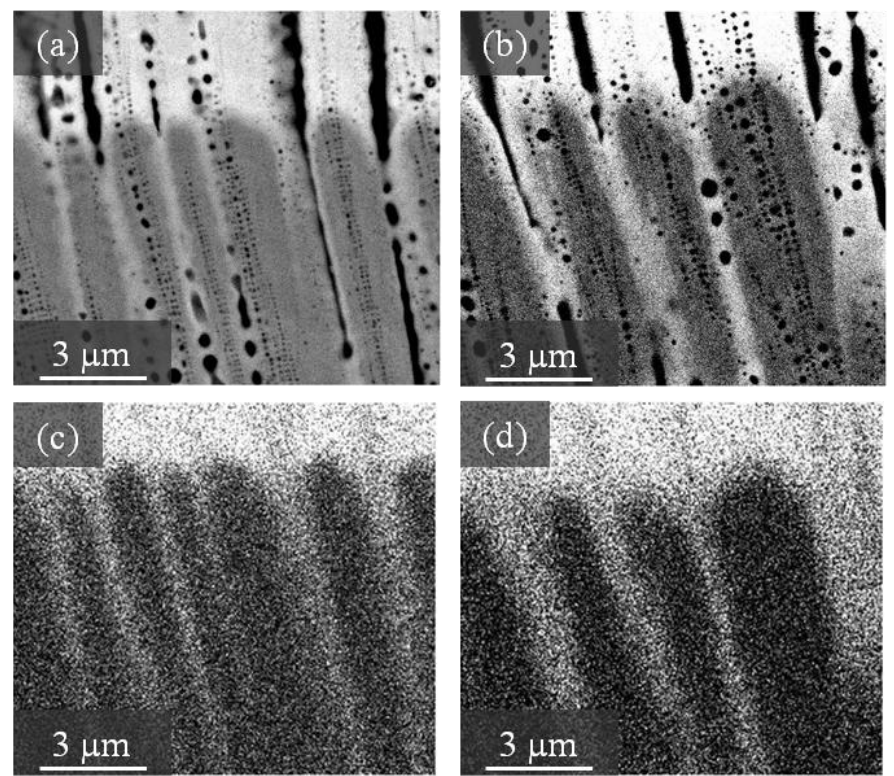

Figure 9. X-SEM micrographs of thicker t' low k-GZO multilayer (Matrix 6) on $\mathrm{Al}_{2} \mathrm{O}_{3}$ substrate showing one interface $\mathrm{GZO} / \mathrm{t}$ ' low $\mathrm{k}$ after isothermal annealing at $1316^{\circ} \mathrm{C}$ for $(\mathrm{a} / \mathrm{c}) 100$ and (b/d) 500 hours with EDS mapping of Gadolinium shown in (c) and (d). 
Table 1. Fabricated TBCs

Figure 1. Plot of thermal conductivity and maximum thermal conductivity for the TBC systems shown in Table 1

Figure 2. Surface SEM micrographs of (a) Matrix 1: Std. YSZ, (b) Matrix 2: $t$ ' low k, (c) Matrix 3: GZO and (d) Matrix 4: t' low k-GZO multilayer after thermal conductivity tests

Figure 3. X- SEM micrographs of (a) Matrix 1: Std. YSZ, (b) Matrix: 2 t' low k, (c) Matrix 3: GZO and (d) Matrix 4: t' low k-GZO multilayer after thermal conductivity tests

Figure 4. X- SEM micrographs t' low k-GZO multilayer (Matrix 5) after thermal conductivity tests

Figure 5. Surface SEM micrographs of Matrix 6: t' low k-GZO thicker multilayer (a) before and (b) after thermal conductivity test.

Figure 6. X-SEM micrographs of as-deposited thicker t' low k-GZO multilayer (Matrix 6) on $\mathrm{Al}_{2} \mathrm{O}_{3}$ substrate at two different magnifiations

Figure 7. Surface SEM micrographs of thicker t' low k-GZO multilayer (Matrix 6) on alumina substrate after annealing at $1316^{\circ} \mathrm{C}$ for (a) 20, (b) 100 and (c) $500 \mathrm{hrs}$.

Figure 8. X-SEM micrographs of thicker t' low k-GZO multilayer (Matrix 6) on $\mathrm{Al}_{2} \mathrm{O}_{3}$ substrate after isothermal annealing at $1316^{\circ} \mathrm{C}$ for (a) 20, (b) 100 and (c) 500 hours.

Figure 9. X-SEM micrographs of thicker t' low k-GZO multilayer (Matrix 6) on $\mathrm{Al}_{2} \mathrm{O}_{3}$ substrate showing one interface $\mathrm{GZO} / \mathrm{t}$ ' low $\mathrm{k}$ after isothermal annealing at $1316^{\circ} \mathrm{C}$ for $(\mathrm{a} / \mathrm{c}) 100$ and (b/d) 500 hours with EDS mapping of Gadolinium shown in (c) and (d). 


\section{FIGURE CAPTIONS}

Figure 1. Plot of thermal conductivity and maximum thermal conductivity for the TBC systems shown in Table 1

Figure 2. Surface SEM micrographs of (a) Matrix 1: Std. YSZ, (b) Matrix 2: t' low k, (c) Matrix 3: GZO and (d) Matrix 4: t' low k-GZO multilayer after thermal conductivity tests

Figure 3. X- SEM micrographs of (a) Matrix 1: Std. YSZ, (b) Matrix: 2 t' low k, (c) Matrix 3: GZO and (d) Matrix 4: t' low k-GZO multilayer after thermal conductivity tests

Figure 4. X-SEM micrographs t' low k-GZO multilayer (Matrix 5) after thermal conductivity tests

Figure 5. Surface SEM micrographs of Matrix 6: t' low k-GZO thicker multilayer (a) before and (b) after thermal conductivity test.

Figure 6. X-SEM micrographs of as-deposited thicker t' low k-GZO multilayer (Matrix 6) on $\mathrm{Al}_{2} \mathrm{O}_{3}$ substrate at two different magnifiations

Figure 7. Surface SEM micrographs of thicker t' low k-GZO multilayer (Matrix 6) on alumina substrate after annealing at $1316^{\circ} \mathrm{C}$ for (a) 20, (b) 100 and (c) $500 \mathrm{hrs}$.

Figure 8. X-SEM micrographs of thicker t' low k-GZO multilayer (Matrix 6) on $\mathrm{Al}_{2} \mathrm{O}_{3}$ substrate after isothermal annealing at $1316^{\circ} \mathrm{C}$ for (a) 20 , (b) 100 and (c) 500 hours.

Figure 9. X- SEM micrographs of thicker t' low k-GZO multilayer (Matrix 6) on $\mathrm{Al}_{2} \mathrm{O}_{3}$ substrate showing one interface $\mathrm{GZO} / \mathrm{t}$ ' low $\mathrm{k}$ after isothermal annealing at $1316^{\circ} \mathrm{C}$ for $(\mathrm{a} / \mathrm{c}) 100$ and (b/d) 500 hours with EDS mapping of Gadolinium shown in (c) and (d). 